
$\mathbf{R}_{\text {ESEARCH }} \mathbf{P}_{\text {APER }} \longrightarrow \frac{\text { FOOD SCIENCE }}{\text { RESEARCH JOURAL }}$
ISSN-0976-1276 - Visit us : www.researchjournal.co.in Volume $11 \mid$ Issue 2 | October, 2020|181-185 DOI : $10.15740 / \mathrm{HAS} / \mathrm{FSRJ} / 11.1 / 181-185$

\title{
Opinion of parents regarding the need to provide sex education to adolescents of Mehsana city
}

\author{
$\mathrm{J}_{\mathrm{iju}}$ N.Vyas, Neha Tiwari and Neeta Chaudhari
}

The present study was conducted to find out parent's opinion regarding need for providing sex education to adolescents. The sample of the study comprised 120 parents of Mehsana city, whose children were 13 to 16 yrs. This study was carried out in the Mehsana city of Gujarat State. The sample selected was purposive in nature and selected randomly. The interview method was used as effective tool for collection of data. Mean score, Arithmetic mean, standard deviation and t-test were used for data analysis.

Key Words : Opinion, Sex education, Adolescent, Parents

How to cite this article : Vyas, Jiju N., Tiwari, Neha and Chaudhari, Neeta (2020). Opinion of parents regarding the need to provide sex education to adolescents of Mehsana city. Food Sci. Res. J., 11(2): 181-185, DOI : 10.15740/HAS/FSRJ/11.2/181-185.Copyright@ 2020: Hind Agri-Horticultural Society.

Associate Authors' :

Jiju N. Vyas, Aspee College of Home Science and Nutrition, Sardarkrushinagar Dantiwada Agricultural University, Dantiwada (Gujarat) India

Neeta Chaudhari, Children Univeristy, Gandhi Nagar (Gujarat) India 